\title{
Cost of Manufacturing for Recombinant Snakebite Antivenoms
}

\author{
Timothy Patrick Jenkins* and Andreas Hougaard Laustsen* \\ Department of Biotechnology and Biomedicine, Technical University of Denmark, Lyngby, Denmark
}

\section{OPEN ACCESS}

Edited by:

Nikolaos E. Labrou,

Agricultural University of Athens,

Greece

Reviewed by:

Anjana Silva,

Rajarata University of Sri Lanka,

Sri Lanka

Choo Hock Tan,

University of Malaya, Malaysia

${ }^{*}$ Correspondence:

Timothy Patrick Jenkins

tpaje@dtu.dk

Andreas Hougaard Laustsen ahola@bio.dtu.dk

Specialty section:

This article was submitted to

Industrial Biotechnology,

a section of the journal

Frontiers in Bioengineering and

Biotechnology

Received: 25 March 2020

Accepted: 04 June 2020

Published: 10 July 2020

Citation:

Jenkins TP and Laustsen AH (2020) Cost of Manufacturing

for Recombinant Snakebite

Antivenoms.

Front. Bioeng. Biotechnol. 8:703.

doi: 10.3389/fbioe.2020.00703
Snakebite envenoming is a neglected tropical disease that affects millions of people across the globe. It has been suggested that recombinant antivenoms based on mixtures of human monoclonal antibodies, which target key toxins of medically important snake venom, could present a promising avenue toward the reduction of morbidity and mortality of envenomated patients. However, since snakebite envenoming is a disease of poverty, it is pivotal that next-generation therapies are affordable to those most in need; this warrants analysis of the cost dynamics of recombinant antivenom manufacture. Therefore, we present, for the first time, a bottom-up analysis of the cost dynamics surrounding the production of future recombinant antivenoms based on available industry data. We unravel the potential impact that venom volume, abundance of medically relevant toxins in a venom, and the molecular weight of these toxins may have on the final product cost. Furthermore, we assess the roles that antibody molar mass, manufacturing and purification strategies, formulation, antibody efficacy, and potential cross-reactivity play in the complex cost dynamics of recombinant antivenom manufacture. Notably, according to our calculations, it appears that such next-generation antivenoms based on cocktails of monoclonal immunoglobulin Gs (IgGs) could be manufacturable at a comparable or lower cost to current plasmaderived antivenoms, which are priced at USD 13-1120 per treatment. We found that monovalent recombinant antivenoms based on IgGs could be manufactured for USD 20-225 per treatment, while more complex polyvalent recombinant antivenoms based on IgGs could be manufactured for USD 48-1354 per treatment. Finally, we investigated the prospective cost of manufacturing for recombinant antivenoms based on alternative protein scaffolds, such as DARPins and nanobodies, and highlight the potential utility of such scaffolds in the context of low-cost manufacturing. In conclusion, the development of recombinant antivenoms not only holds a promise for improving therapeutic parameters, such as safety and efficacy, but could possibly also lead to a more competetive cost of manufacture of antivenom products for patients worldwide.

Keywords: next-generation antivenoms, cost of manufacture, snakebite, envenoming, toxin neutralization, antivenom manufacture, human monoclonal antibodies, alternative protein scaffolds

\section{INTRODUCTION}

The World Health Organization recently reclassified snakebite envenoming as a Category A Neglected Tropical Disease and developed a strategy for reducing the morbidity and mortality for snakebite victims worldwide (Chippaux, 2017; Williams et al., 2019). As an important part of this strategy, research and development on improved 
snakebite envenoming therapies is recommended. In this relation, a promising avenue that has gained interest in recent years, is the use of recombinant antivenoms based on carefully designed mixtures of human monoclonal antibodies targeting key toxins of medically important snake venoms (Laustsen, 2016). Some of the hypothesized benefits of using recombinant antivenoms include a reduced propensity to cause adverse reactions in patients and a higher content of therapeutically active antibodies (Kini et al., 2018). Additionally, recombinant antivenoms have also been hypothesized to be manufacturable at low cost (Laustsen et al., 2016, 2017), which is an important parameter for therapies against neglected tropical diseases. However, one of the challenges that sets snakebite envenoming aside from other indications that are treatable with antibodies is that exceptionally high amounts of antibodies are needed for effective treatment (Laustsen, 2019). Therefore, the cost of manufacture should be a key focal point for recombinant antivenom developers (Laustsen and Dorrestijn, 2018; Knudsen et al., 2019). Yet, so far, this has remained largely unexplored. Currently, the only estimates are based on top-down calculations built on limited knowledge derived from conventional polyclonal plasma-derived antivenoms paired with data from general industrial manufacture of monoclonal antibodies (Laustsen et al., 2017). However, with recent developments in the field of recombinant antivenom research and reports of monoclonal antibodies being effective at low dose in neutralizing key toxins in different animal venoms (Richard et al., 2013; Knudsen and Laustsen, 2018; Laustsen et al., 2018), it is now possible to perform a more fine-grained estimation of the prospective cost of manufacture for recombinant antivenoms. Hence, here we present such estimates for the cost of manufacture for future recombinant antivenoms based on bottom-up calculations, which have the benefit over top-down calculations that more real-life data on antibody efficacy and venom yields can be incorporated. We present different antivenom cost scenarios for vipers and elapids that either inject large or small amounts of venoms, as well as we estimate the manufacturing costs for polyvalent recombinant antivenoms covering multiple snake species. Finally, we compare the theoretical cost of manufacture for the active pharmaceutical ingredient (API) with the cost of manufacture for the final drug product (FDP), as well as explore the relation between cost of manufacture and the molecular sizes of different antibody formats with the purpose of highlighting the influence of the number of toxin binding sites per mass unit for different types of antibodies.

\section{MATERIALS AND METHODS}

\section{Venoms Included in This Study and Definition of Key Toxins}

In this study, we analyzed the theoretical cost of manufacture for recombinant antivenom production for 17 different snake venoms from Asia, Africa, Australia, North America, Central America, and South America. For all of these species, we collated data on the maximum venom yields (dry weight) recorded for each species $\left(m_{\text {yield }}\right)$, protein composition (based on proteomics studies), and estimated percentage of toxins in a given venom that needs to be neutralized for successful clinical outcome ( $r_{\%}$ neutralized; Table 1). $r_{\%}$ neutralized was based on the combined percentage of snake venom metalloproteinases (SVMPs, including sub-families SVMP PI and PIII), snake venom serine proteinases (SVSPs), phospholipases $\mathrm{A}_{2}\left(\mathrm{PLA}_{2} \mathrm{~s}\right)$, threefinger toxins (3FTxs), $\beta$-bungarotoxins, dendrotoxins, C-type lectins, and disintegrins present in the venom; $r_{\%}$ neutralized was set conservatively at the highest value realistically possible.

\section{Average Molar Mass of Toxins}

To calculate the average molar mass $(\mathrm{M})$ of the medically relevant toxins in each venom, the average molar mass of each toxin family $\left(\mathrm{M}_{\text {Tox }}\right.$; Table 2$)$ was based on an average value; specific molecular weight data for each toxin in a proteome is often not available, hence the values were fixed according to parameters accepted by the scientific community (Strong et al., 1976; Harvey, 2001; Calvete et al., 2007b; Serrano, 2012; Wong et al., 2016; Ferraz et al., 2019). M was then multiplied with its relative abundance (Ra) in each respective venom. Upon summation of all values and division by the total $\mathrm{Ra}$ of all toxin families combined (Rasum), an average molar mass for each venom was generated (Eq. 1).

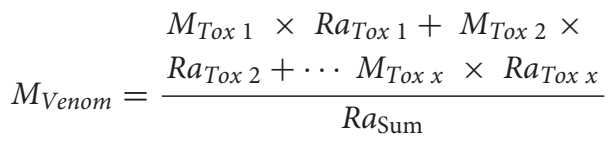

\section{Calculating the Amount of Antibodies Required for Neutralization for a Monovalent Antivenom}

With the previously mentioned variables, we proceeded to calculate the approximate amount of antibodies (Abs) required $\left(\mathrm{m}_{\mathrm{Ab}}\right.$ required; grams) to neutralize each of the venoms included in this study (Eq. 2). $\mathrm{M}_{\mathrm{Ab}}$ designates the molar mass of antibody [for immunoglobulin $\mathrm{G}$ ( $\mathrm{IgG}$ ) this is $150 \mathrm{kDa}$ ]. However, we also wanted to account for fluctuations in venom injected in any given bite $\left(r_{\%}\right.$ injected $)$. Therefore, we included three possible bite scenarios, i.e., $25 \%$ of $m_{\text {yield }}, 50 \%$ of $m_{\text {yield }}$, and $100 \%$ of $m_{\text {yield }}$. We also included three different estimates of how many antibodies would be required to neutralize each toxin, expressed as ratios between toxin-to-antibody $\left(R_{T o x: A b}\right)$, i.e., $2: 1,1: 1$, and 1:3. These ratios were chosen based on previously reported data demonstrating that effective antibodies can neutralize medically relevant toxins at these ratios (Richard et al., 2013; Laustsen et al., 2018; Silva et al., 2018; Calderon et al., 2020).

$$
\begin{gathered}
m_{A b \text { required }}=\frac{m_{\text {yield }} \times r_{\% \text { neutralised }} \times r_{\% \text { injected }}}{M_{\text {Venom }}} \\
\times M_{A b} \times R_{\text {Tox:Ab }}
\end{gathered}
$$

\section{Antibody Manufacturing Strategies}

Different manufacturing approaches can have a significant impact on the manufacturing costs for recombinant monoclonal antibodies $\left(\operatorname{Cost}_{\mathrm{Ab}}\right)$. In this study, estimated costs for three types of manufacturing processes based on Chinese Hamster 
TABLE 1 | Venoms Included in Our Costing Analyses for Recombinant Antivenoms.

\begin{tabular}{|c|c|c|c|c|}
\hline Species & $m_{\text {yield }}$ & $\begin{array}{l}\text { Venom composition (medically relevant } \\
\text { toxins) }\end{array}$ & $r_{\%}$ neutralized & References \\
\hline $\begin{array}{l}\text { Naja naja (proteomics: East India; yield: } \\
\text { India) }\end{array}$ & $0.169 \mathrm{~g}$ & $\mathrm{PLA}_{2} \mathrm{~S}(11.4 \%)$ and 3FTxs (63.8\%) & $75.2 \%$ & Broad et al., 1979; Dutta et al., 2017 \\
\hline $\begin{array}{l}\text { Echis carinatus (proteomics: India; } \\
\text { yield: Iran) }\end{array}$ & $0.04 \mathrm{~g}$ & $\begin{array}{l}\text { SVMPs (45.4\%), SVSPs (0.3\%), disintegrins } \\
\text { (14\%), C-type lectins (23.9\%), and PLA } 2 \text { S } \\
(10.9 \%)\end{array}$ & $94.5 \%$ & Latifi, 1984; Patra et al., 2017 \\
\hline $\begin{array}{l}\text { Bungarus caeruleus (proteomics: South } \\
\text { India; yield:Sri Lanka) }\end{array}$ & $0.024 \mathrm{~g}$ & $\begin{array}{l}\text { SVMPs (4.8\%), SVSPs (0.1\%), PLA } 2 \text { s }(24.7 \%) \text {, } \\
3 F T x s(48.3 \%) \text {, and } \beta \text {-bungarotoxins (12.9\%) }\end{array}$ & $90.8 \%$ & Williams et al., 2011; Patra et al., 2019 \\
\hline $\begin{array}{l}\text { Daboia russelii (proteomics: East India; } \\
\text { yield: Sri Lanka) }\end{array}$ & $0.115 \mathrm{~g}$ & $\begin{array}{l}\text { SVMPs (18.8\%), SVSPs (14.1\%), disintegrins } \\
(1.8 \%) \text {, C-type lectins (11.6\%), and PLA } 2 \text { S } \\
(21.9 \%)\end{array}$ & $68 \%$ & Williams et al., 2011; Kalita et al., 2018 \\
\hline $\begin{array}{l}\text { Pseudechis australis (proteomics: } \\
\text { Australia; yield: Australia) }\end{array}$ & $0.787 \mathrm{~g}$ & SVMPs (53\%) and PLA 2 s (18.5\%) & $71.5 \%$ & $\begin{array}{l}\text { Mirtschin et al., 2006; Georgieva et al., } \\
2011\end{array}$ \\
\hline $\begin{array}{l}\text { Micrurus nigrocinctus (proteomics: } \\
\text { Costa Rica; yield: Costa Rica) }\end{array}$ & $0.008 \mathrm{~g}$ & $\begin{array}{l}\text { SVMPs (4.3\%), PLA } 2 \text { s (48\%), C-type lectins } \\
(2.2 \%) \text {, and } 3 F T x s(38 \%)\end{array}$ & $92.5 \%$ & $\begin{array}{l}\text { Chacón et al., 2012; Fernández et al., } \\
2011\end{array}$ \\
\hline $\begin{array}{l}\text { Crotalus adamanteus (proteomics: } \\
\text { United States; yield: Florida) }\end{array}$ & $0.41 \mathrm{~g}$ & $\begin{array}{l}\text { SVMPs (16\%), SVSPs (25\%), C-type lectins } \\
(5 \%) \text {, and PLA } 2 \text { s (28\%) }\end{array}$ & $97 \%$ & Broad et al., 1979; Margres et al., 2014 \\
\hline $\begin{array}{l}\text { Bothrops atrox (proteomics: South } \\
\text { America; yield: South America - } \\
\text { average) }\end{array}$ & $0.2 \mathrm{~g}$ & $\begin{array}{l}\text { SVMPs (83\%; PI 14\% and PII 69\%), SVSPs } \\
(4.5 \%) \text {, disintegrins (0.2\%), C-type lectins } \\
(0.1 \%) \text {, and } \mathrm{PLA}_{2} \mathrm{~S}(10 \%)\end{array}$ & $97.8 \%$ & O'Shea, 2005; Calvete et al., 2011 \\
\hline $\begin{array}{l}\text { Bitis arietans (proteomics: Africa; yield: } \\
\text { Africa) }\end{array}$ & $0.29 \mathrm{~g}$ & $\begin{array}{l}\text { SVMPs (38.5\%), SVSPs (19.5\%), disintegrins } \\
(17.8 \%), \text { C-type lectins }(13.2 \%) \text {, and PLA } 2 \text { S } \\
(4.3 \%)\end{array}$ & $93.2 \%$ & $\begin{array}{l}\text { Juárez et al., 2006; Mirtschin et al., } \\
2006\end{array}$ \\
\hline $\begin{array}{l}\text { Bitis gabonica (proteomics: Africa; } \\
\text { yield: Africa) }\end{array}$ & $0.24 \mathrm{~g}$ & $\begin{array}{l}\text { SVMPs (22.9\%), SVSPs (26.4\%), C-type lectins } \\
(14.3 \%) \text {, and PLA } 2 \text { s (11.4\%) }\end{array}$ & $75 \%$ & $\begin{array}{l}\text { Marsh and Whaler, 1984; Calvete et al., } \\
\text { 2007a }\end{array}$ \\
\hline $\begin{array}{l}\text { Echis ocellatus (proteomics: Nigeria; } \\
\text { yield: Nigeria) }\end{array}$ & $0.016 \mathrm{~g}$ & $\begin{array}{l}\text { SVMPs (61.4\%; PI 6.3\% and PIII 55.1\%), } \\
\text { SVSPs (1.9\%), disintegrins (6.8\%), C-type } \\
\text { lectins (7\%), and PLA } 2 \text { s (11.7\%) }\end{array}$ & $89.8 \%$ & $\begin{array}{l}\text { Wagstaff et al., 2009; Williams et al., } \\
2011\end{array}$ \\
\hline $\begin{array}{l}\text { Echis leucogaster (E. ocellatus used as } \\
\text { proxy; proteomics: Nigeria; yield: } \\
\text { Nigeria) }\end{array}$ & $0.016 \mathrm{~g}$ & $\begin{array}{l}\text { SVMPS (61.4\%; PI 6.3\% and PIII 55.1\%), } \\
\text { SVSPs (1.9\%), disintegrins (6.8\%), C-type } \\
\text { lectins (7\%), and PLA } 2 \text { S (11.7\%) }\end{array}$ & $89.8 \%$ & $\begin{array}{l}\text { Wagstaff et al., 2009; Williams et al., } \\
2011\end{array}$ \\
\hline $\begin{array}{l}\text { Dendroaspis polylepis (proteomics: } \\
\text { Tanzania; yield: East Africa) }\end{array}$ & $0.026 \mathrm{~g}$ & $\begin{array}{l}\text { SVMPs (3.2\%), 3FTxs (31\%), and dendrotoxins } \\
(20 \%)\end{array}$ & $54.2 \%$ & Williams et al., 2011; Petras et al., 2016 \\
\hline $\begin{array}{l}\text { Dendroaspis jamesoni (proteomics: } \\
\text { Cameroon; yield: Africa) }\end{array}$ & $0.12 \mathrm{~g}$ & $3 F T x s(80 \%)$, and dendrotoxins (12.5\%) & $92.5 \%$ & O'Shea, 2005; Ainsworth et al., 2018 \\
\hline $\begin{array}{l}\text { Dendroaspis viridis (proteomics: Togo; } \\
\text { yield: Africa) }\end{array}$ & $0.1 \mathrm{~g}$ & $3 F T x s(78 \%)$, and dendrotoxins $(2.1 \%)$ & $80.1 \%$ & O’Shea, 2005; Ainsworth et al., 2018 \\
\hline $\begin{array}{l}\text { Naja haje (proteomics: Morocco; yield: } \\
\text { Africa) }\end{array}$ & $0.3 \mathrm{~g}$ & SVMPs (9\%), PLA 2 S (4\%), and 3FTxs (60\%) & $73 \%$ & O'Shea, 2005; Malih et al., 2014 \\
\hline $\begin{array}{l}\text { Naja nigricollis (proteomics: W Africa; } \\
\text { yield: Nigeria) }\end{array}$ & $0.362 \mathrm{~g}$ & $\begin{array}{l}\text { SVMPs (2.4\%; PIII 2.4\%), PLA } 2 \text { s (21.9\%), and } \\
3 \text { FTxs (73.3\%) }\end{array}$ & $97.6 \%$ & Williams et al., 2011; Petras et al., 2011 \\
\hline $\begin{array}{l}\text { Naja melanoleuca (proteomics: } \\
\text { Uganda; yield: Africa) }\end{array}$ & $1.1 \mathrm{~g}$ & $\begin{array}{l}\text { SVMPs (9.7\%), PLA } 2 \text { s (12.9\%), and 3FTxs } \\
(57.1 \%)\end{array}$ & $79.7 \%$ & $\begin{array}{l}\text { Mirtschin et al., 2006; Lauridsen et al., } \\
2017\end{array}$ \\
\hline
\end{tabular}

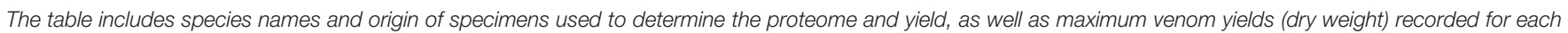

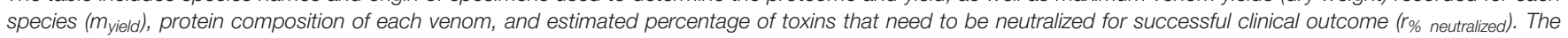

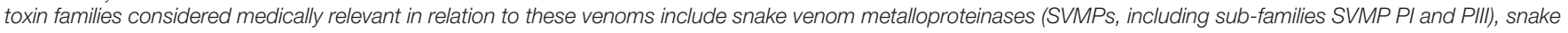
venom serine proteinases (SVSPS), phospholipases $A_{2}\left(P L A_{2} S\right.$ ), three-finger toxins (3FTXs), $\beta$-bungarotoxins, dendrotoxins, C-type lectins, and disintegrins.

Ovary (CHO) cell cultivation were employed: The fed-batch process (nutrients for the $\mathrm{CHO}$ cells are supplied for a complete manufacturing process, followed by harvest of the entire batch), the hybrid process (cultivation is performed in a fed-batch bioreactor, followed by continuous or semicontinuous purification of the produced antibodies), and the continuous perfusion process (cultivated cells are retained in the bioreactor, while the growth medium containing the antibodies is continuously substituted with fresh medium in a perfusion bioreactor; the used medium undergoes a continuous or semi-continuous purification process in order to isolate the antibodies; Figure 1; Hammerschmidt et al., 2014; Walsh, 2014). Each manufacturing method was then combined with a downstream process based on either chromatographic or caprylic acid purification. The approximate costs for each process can be found in Table 3 derived from Laustsen et al. (2017), which assume an annual production volume of $500 \mathrm{~kg}$ of antibodies. The cost estimates for the different manufacturing strategies are based on available industrial data as well as prior discussions 
TABLE 2 | Average Molar Masses of All Toxin Families Considered to be Medically Relevant.

\begin{tabular}{lll}
\hline TOXIN family & Molar mass & References \\
\hline SVMP & $50 \mathrm{kDa}$ & Ferraz et al., 2019 \\
SVMP (PI) & $25 \mathrm{kDa}$ & Ferraz et al., 2019 \\
SVMP (PIII) & $80 \mathrm{kDa}$ & Ferraz et al., 2019 \\
SVSP & $30 \mathrm{kDa}$ & Serrano, 2012 \\
PLA 2 & $14 \mathrm{kDa}$ & Ferraz et al., 2019 \\
3FTx & $8 \mathrm{kDa}$ & Wong et al., 2016 \\
$\beta$-bungarotoxin & $16 \mathrm{kDa}$ & Strong et al., 1976 \\
Dendrotoxins & $7 \mathrm{kDa}$ & Harvey, 2001 \\
C-type lectins & $28 \mathrm{kDa}$ & Calvete et al., 2007a \\
Disintegrins & $9.5 \mathrm{kDa}$ & Calvete et al., 2007a \\
\hline
\end{tabular}

This includes snake venom metalloproteinases (SVMPs, including sub-families SVMP PI and PIII), snake venom serine proteinases (SVSPS), phospholipases $A_{2}$ $\left(P L A_{2} S\right)$, three-finger toxins (3FTXs), $\beta$-bungarotoxins, dendrotoxins, C-type lectins, and disintegrins.

with five independent experts from five different companies in Germany, Denmark, and the United Kingdom (Farid, 2007; Rasmussen et al., 2012; Hammerschmidt et al., 2014; Walsh, 2014; Klutz et al., 2015; Laustsen et al., 2017). The assumed volume was based on a previous assessment for what the need for a sub-Saharan antivenom would be to establish the approximate scale of manufacture. Here, it was chosen to also use the manufacturing data at this scale to allow for a direct comparison with the previously reported top-down cost assessment for recombinant antivenoms (Laustsen et al., 2017). Depending on the manufacturing and purification process employed, the cost of the recombinant monoclonal antibodies will be either higher or lower. Therefore we calculated the exact cost impact each strategy would have on a recombinant antivenom. However, for final cost analyses of recombinant antivenoms, only the hybrid process combined with caprylic acid precipitation (hybrid cap. $_{\text {. }}$ ) was employed, as it was projected to be the most cost-competitive approach and, thus, potentially most promising for future recombinant antivenom manufacture. It is noteworthy that whilst purification via caprylic acid is less expensive than chromatography, the latter can be employed to obtain a product of even higher purity.

\section{The Cost of Goods Manufactured of Active Pharmaceutical Ingredient $\left(\mathrm{COGM}_{\mathrm{API}}\right)$ and the Final Drug Product (COGM FDP)}

When we calculate the product of $\operatorname{Cost}_{\mathrm{Ab}}$ and $\mathrm{m}_{\text {Abrequired }}$, we obtain the Cost of Goods Manufactured of Active Pharmaceutical Ingredient for a full treatment of a given snakebite (COGM $\mathrm{API}$; Eq. 3).

$$
\operatorname{COGM}_{A P I}=\operatorname{Cost}_{A b} \times m_{A b \text { required }}
$$

We can then move on to calculate the Cost of Goods Manufactured for the Final Drug Product for a full treatment of a given snakebite (COGM $\left.\mathrm{CDP}_{\mathrm{F}}\right)$. For this, we used cost estimations for formulation and packaging, also known as Fill Finish, from a previous study (Laustsen et al., 2017). The authors estimated that for future recombinant antivenoms an average of four vials per treatment would be optimal for a treating clinician, since it allows for flexible dosing, and that the associated cost is five USD/vial, i.e., a total of USD 20, to the COGM API (Eq. 4).

$$
C O G M_{F D P}=C O G M_{A P I}+U S D 20
$$

\section{Cost of Recombinant Polyvalent Antivenoms}

To estimate the cost of recombinant polyvalent antivenoms, we used two examples, namely a "simple" recombinant antivenom against the "Big 4" of India, i.e., Naja naja, Echis carinatus, Daboia russelii, and Bungarus caerulus, and a more complex one, including 10 different species. The latter is an estimation of the cost of manufacture for a recombinant (biosimilar) antivenom mimicking Sanofi Pasteur's FAV-Afrique, a former high-quality polyvalent antivenom indicated for a wide range of species from sub-Saharan Africa. Here, our calculations include venoms from Bitis arietans, B. gabonica, E. leucogaster, E. ocellatus, Dendroaspis polylepis, D. jamesoni, D. viridis, N. haje, N. nigricollis, and $N$. melanoleuca. We assumed that $m_{\text {yield }}$ equated to $50 \%$ of the maximum yield and also wanted to account for potential cross-reactivity of antibodies present in the hypothetical polyvalent antivenom $\left(r_{\text {cross-react }}\right)$ and, therefore, calculated COGM API $_{\text {for three }}$ different scenarios with $0 \%$ cross-reactivity, $25 \%$ cross-reactivity, and $50 \%$ cross-reactivity for the antibodies included in the polyvalent recombinant antivenom. The estimations made toward cross-reactivity were based on the extremes of having either no cross-reactivity or a maximum of $50 \%$ cross-reactivity to capture the full spectrum of likely cross-reactivities. In the case, where no cross-reactivity is present, antibodies are needed for all toxins from all venoms. In the opposite case with $100 \%$ cross-reactivity, the antibodies needed for neutralizing the venom with the highest amount of toxins $\left(n_{\text {venommax }}\right.$ ) would (due to their cross-reactivity) be able to neutralize all other toxins from other venoms. Consequently, we can calculate the total antibodies (in mol) needed for neutralizing all venoms $\left(n_{\text {Tox }}\right)$. This is described by the following equation (Eq. 5):

$$
\begin{aligned}
n_{\text {Tox }} & =n_{\text {venom max }}+\sum_{n_{\text {venom min }}}^{n_{\text {venom max }-1}} n_{\text {venom } x} \\
& \times\left(1-r_{\text {cross-react }}\right)
\end{aligned}
$$

Finally, COGM $\mathrm{FDP}_{\mathrm{P}}$ was calculated as described above. Here, $M_{\mathrm{Ab}}$ required was calculated using $n_{\mathrm{Tox}}$ and $M_{\mathrm{Ab}}$ (Eq 6).

$$
\begin{aligned}
\mathrm{COGM}_{\mathrm{FDP}, \text { polyvalent }} & =n_{\text {Tox }} \times M_{A b} \times R_{\text {Tox }: A b} \\
& \times \operatorname{Cost}_{A b, \text { hybrid } / \text { cap }}+\text { USD } 20
\end{aligned}
$$




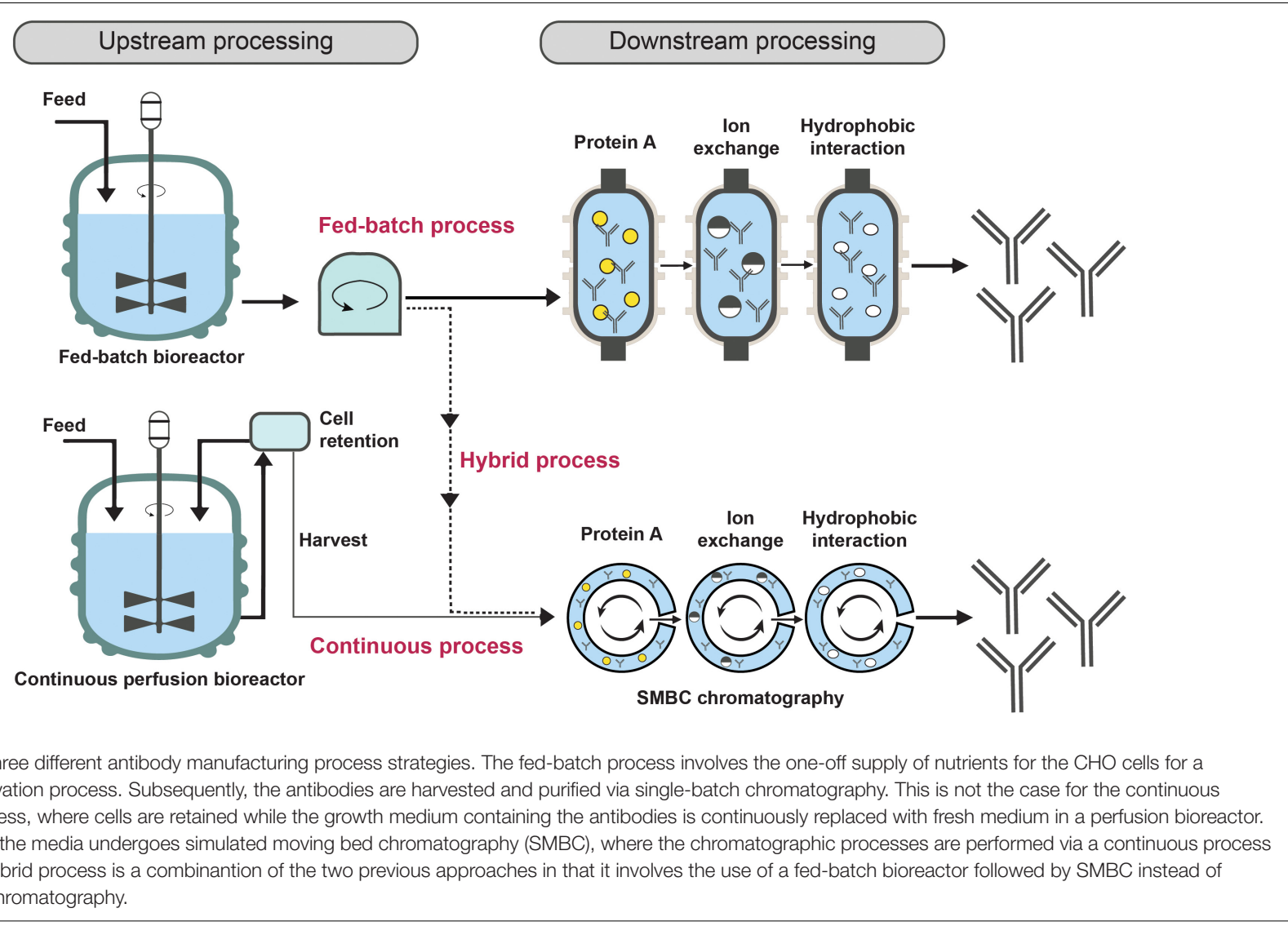

TABLE 3 | Cost estimates for different antibody manufacturing strategies, followed by either chromatographic or caprylic acid purification.

\begin{tabular}{llcc}
\hline Cost $_{\mathrm{Ab}}$ & \multicolumn{2}{c}{ Downstream process } \\
\cline { 3 - 4 } & & Chromatography & Caprylic acid \\
\hline \multirow{3}{*}{ Upstream process } & Fed-Batch & $62 \mathrm{USD} / \mathrm{g}$ & $46 \mathrm{USD} / \mathrm{g}$ \\
& Hybrid & $47 \mathrm{USD} / \mathrm{g}$ & $33 \mathrm{USD} / \mathrm{g}$ \\
& Continuous perfusion & $89 \mathrm{USD} / \mathrm{g}$ & $42 \mathrm{USD} / \mathrm{g}$ \\
\hline
\end{tabular}

These estimates assume an annual production volume of $500 \mathrm{~kg}$ of antibodies.

\section{Costing Recombinant Antivenom Products Based on Alternative Antibody Formats}

We also wanted to understand the impact of the small molar mass of alternative antibody formats, such as Fragment antigen binding $(\mathrm{Fab} ; 50 \mathrm{kDa})$ and single-chain variable fragments (scFvs, $25 \mathrm{kDa}$ ), as well as alternative protein scaffolds, e.g., designed ankyrin repeat proteins (DARPins; $15 \mathrm{kDa}$ ), singledomain antibodies (nanobodies; $15 \mathrm{kDa}$ ), and Avimers (4 kDa). Although, some of these antibodies and binding proteins would likely be produced by different manufacturing processes, such as microbial fermentation, which may be even more costcompetitive, we decided to calculate the costs using the same parameters (with exception of $\mathrm{M}_{\mathrm{Ab}}$ ) as for IgGs (33 USD/g) to facilitate direct cost comparison as a function of molecular sizes alone. To understand the impact that different molar masses can have on the COGM FDP of a potentially expensive antivenom, we investigated this in the context of a recombinant FAV-Afrique biosimilar antivenom. Here, we assumed 1:1/1:3 toxin-to-antibody ratios and $25 \% / 0 \%$ cross-reactivity to simulate an "expected" and a "worst-case" scenario, respectively.

\section{RESULTS AND DISCUSSION}

Understanding the dynamics of the manufacturing costs for nextgeneration antivenoms is pivotal toward developing effective, but also cost-competitive therapies for snakebite victims. Therefore, in the following, we present key variables to consider when assessing potential manufacturing costs for recombinant antivenoms using a bottom-up approach and conclude that they indeed represent a promising solution for next-generation snakebite envenoming therapy.

\section{Impact of Antibody Manufacturing Strategies and Formulation on the COGM for Recombinant Antivenom Therapy}

Many different strategies exist for the manufacture of recombinant antibodies. These utilize different downstream processes (such as chromatography and caprylic acid precipitation) and have different cost structures (Figure 2A). Based on available data from the scientific literature, and 


\section{A}
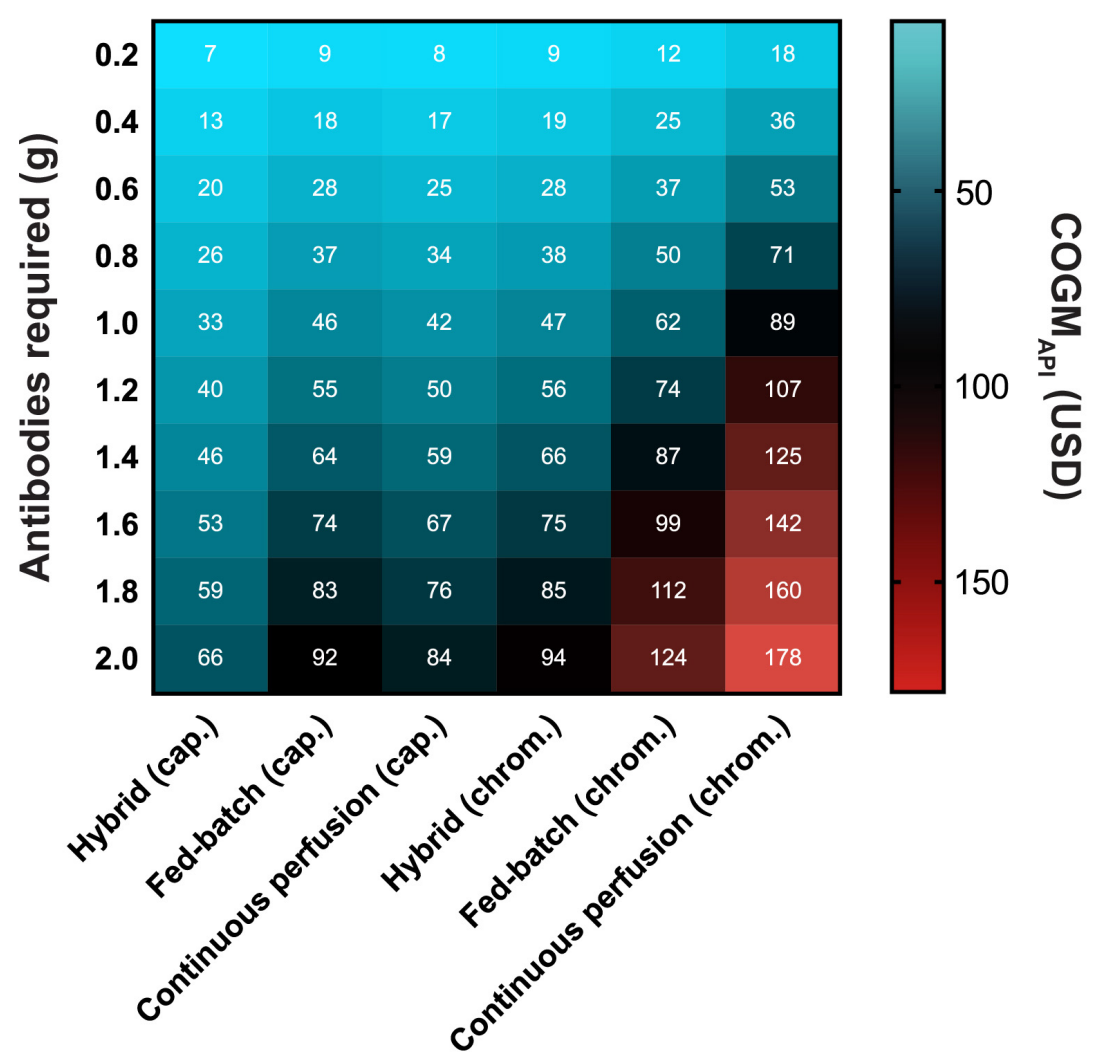

B

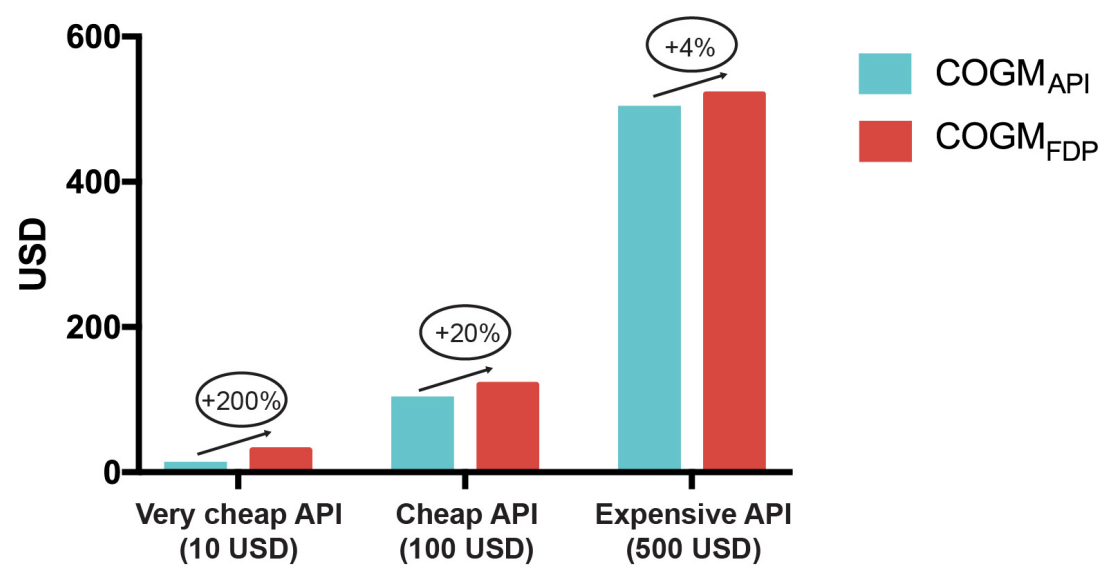

FIGURE 2 | Cost of manufacture for recombinant antivenoms in relation to manufacturing process and treatment dose. (A) Cost impact of different manufacturing strategies in relation to how many grams of antibodies are required for a full antivenom treatment of a snakebite envenoming case. The three upstream processes included are the fed-batch process, the hybrid process, and the continuous perfusion process. Each upstream process was combined with either chromatographic or caprylic acid purification steps to calculate the respective Cost of Goods Manufactured of the Active Pharmaceutical Ingredient (COGMAPI) per treatment. The white numbers in the cells correspond to the exact COGM $\mathrm{API}$ corresponding to that particular cell. (B) The impact of formulation on the final drug product (FDP) cost for very cheap, cheap, and expensive COGM $\mathrm{API}$.

assuming an annual production volume of $500 \mathrm{~kg}$ of antibodies, the most costly manufacturing strategy for recombinant antibodies is continuous perfusion followed by chromatography, which is estimated to have a COGM API of USD 89 per gram of antibody. Conversely, the most inexpensive strategy may involve a combination of the hybrid upstream process and caprylic acid purification (USD 33 per gram of antibody). This suggests that, from a cost perspective, the latter approach might be the most applicable for manufacture of recombinant antivenoms, for which cost is a major concern, as snakebite envenoming is most 


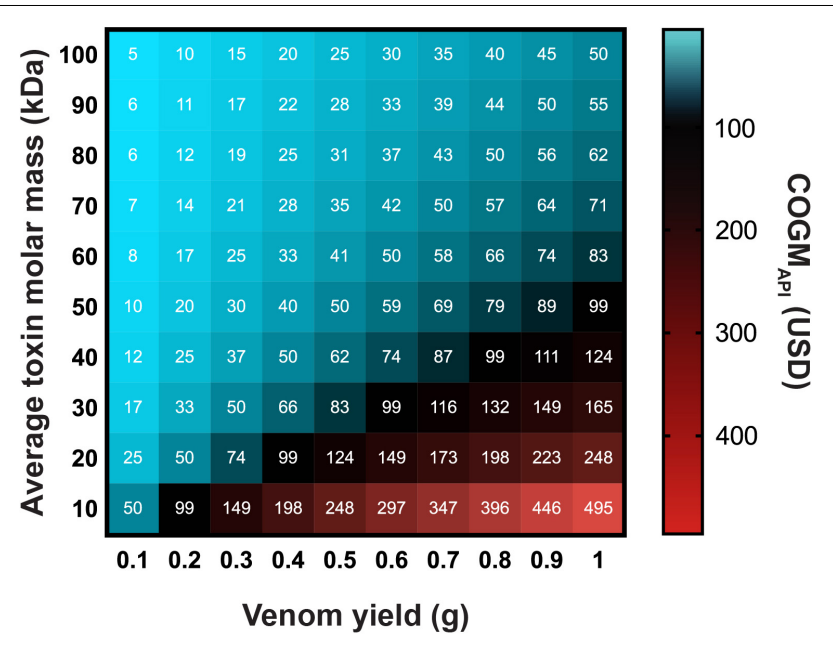

FIGURE 3 | How the molecular weight and amount of venom to be neutralized affect the Cost of Goods Manufactured of the Active

Pharmaceutical Ingredient (COGM $\mathrm{API}$ ) for recombinant antivenoms. The heat map includes three variables, namely the amount of venom to be neutralized in grams, the average molecular mass of the venom toxins in $\mathrm{kDa}$, and the COGM $_{\text {API }}$ in USD. The white numbers in the cells correspond to the exact COGM $_{\text {API }}$ corresponding to that particular cell.

prevalent in rural impoverished areas of the tropics (Harrison et al., 2009). Our calculations also demonstrate the impact of formulation on the $\mathrm{COGM}_{\mathrm{FDP}}$ (Figure 2B). Unsurprisingly, formulation costs barely affect the COGMFDP of a product with a high $\mathrm{COGM}_{\mathrm{API}}$, whilst it could lead to a $200 \%$ cost increase for antivenom products with a very low (USD 10) COGM $_{\text {API }}$. Therefore, formulation costs are critical to take into consideration when manufacturing costs are low.

\section{How Molar Mass and Venom Quantity Affect COGM API}

The molar mass and amount of a given venom to be neutralized for a given snakebite case are also important cost-affecting factors (Figure 3). An amount of venom comprising toxins with lower molar masses will require more mols of antibodies for neutralization compared to the same amount of venom comprising toxins with higher molar masses. This is further amplified by the absolute amounts of venom being injected by a given snake. Consequently, bites from snakes that produce large volumes of venom comprising toxins with low average molar mass require the most antibodies and are, therefore, the most costly to neutralize. In contrast, bites from snakes that produce small volumes of venom comprising toxins with high average molar mass require the least antibodies and are the least costly to neutralize.

\section{COGM $_{\text {FDP }}$ for Monovalent Recombinant Antivenoms}

Based on our previous calculations, we quantified the cost of four different putative monovalent recombinant antivenoms (Figure 4). These calculations were based on the assumption that the recombinant antibodies are manufactured via the hybrid process followed by caprylic acid precipitation. The calculations were conducted for three different toxin-to-antibody ratios (i.e., $2: 1,1: 1$, and $1: 3$ ) and assumed that either $25 \%, 50 \%$, or $100 \%$ of the maximum venom yield (dry weight) is injected into a victim. Furthermore, to understand the above-mentioned cost dynamics of average venom toxin molar mass and venom amount, we included four snakes with different types of venoms and venom yields. The first snake ( $M$. nigrocinctus) has a venom comprising toxins with a comparatively small average molar mass $(13 \mathrm{kDa})$ and can only produce a very small volume of venom $(0.008 \mathrm{~g})$, the second snake (B. atrox) presents a venom comprising toxins with a large average molar mass $(63 \mathrm{kDa})$, but still at a relatively small volume $(0.2 \mathrm{~g})$, the third snake (C. adamanteus) has a venom with a comparatively lower molar mass $(23 \mathrm{kDa})$, but can produce $0.41 \mathrm{~g}$ of its venom, and finally $P$. australis venom has an average molar mass for its venom toxins of $40 \mathrm{kDa}$ and can produce up to $0.79 \mathrm{~g}$ of the venom. It is notable that for both $M$. nigrocinctus and $B$. atrox, antibody efficacy and percentage of maximum venom yield injected had no major impact on the $\mathrm{COGM}_{\mathrm{FDP}}$ of the respective monovalent antivenom (Figure 4), as the cost of formulation and packaging is the main cost driver. This was not the case when calculating the costs for the two other monovalent antivenoms against $C$. adamanteus and $P$. australis. Whilst the percentage of volume injected had a significant impact on the COGM $\mathrm{FDP}$ for both antivenoms, the efficacy of the antibodies (reflected by the toxin-to-antibody ratio) had the largest effect on the cost. For instance, a monovalent recombinant antivenom of $C$. adamanteus that contained highly efficacious antibodies (i.e., one antibody per two toxins) would cost USD 29 per treatment when assuming $25 \%$ of max venom yield is injected and USD 54 when calculating with $100 \%$ of max venom yield injected. However, when assuming that three antibodies are required per toxin, the cost increases to USD 71 (25\% of $\max$ venom yield injected) and USD 225 (100\% of max venom yield injected), respectively.

\section{COGM $_{\text {FDP }}$ for Two Polyvalent Recombinant Antivenoms}

Whilst monovalent antivenoms fulfill an important role in certain regions of the world (such as Australia), polyvalent antivenoms that are effective against a wide range of different venoms are key to solving the global crisis of snakebite envenoming (Gutiérrez et al., 2017). Polyvalent antivenoms eliminate the need for medical practioners to identify the species of venomous snake that bit the patient and, thus, removes the issue of diagnostic uncertainty for the medical practioner (Gutiérrez et al., 2017). The drawback to polyvalent recombinant antivenoms is the complexity of developing them, since it requires that more monoclonal antibodies are included in the formulation of the antivenom, and likely also that the individual antibodies are broadly neutralizing, for the antivenom to be efficacious against many different venoms. To estimate the costs of polyvalent recombinant antivenoms, we explored both a simple antivenom that could neutralize the four most medically relevant snakes in India (i.e., the "Big 4": N. naja, B. caeruleus, D. russelii, 


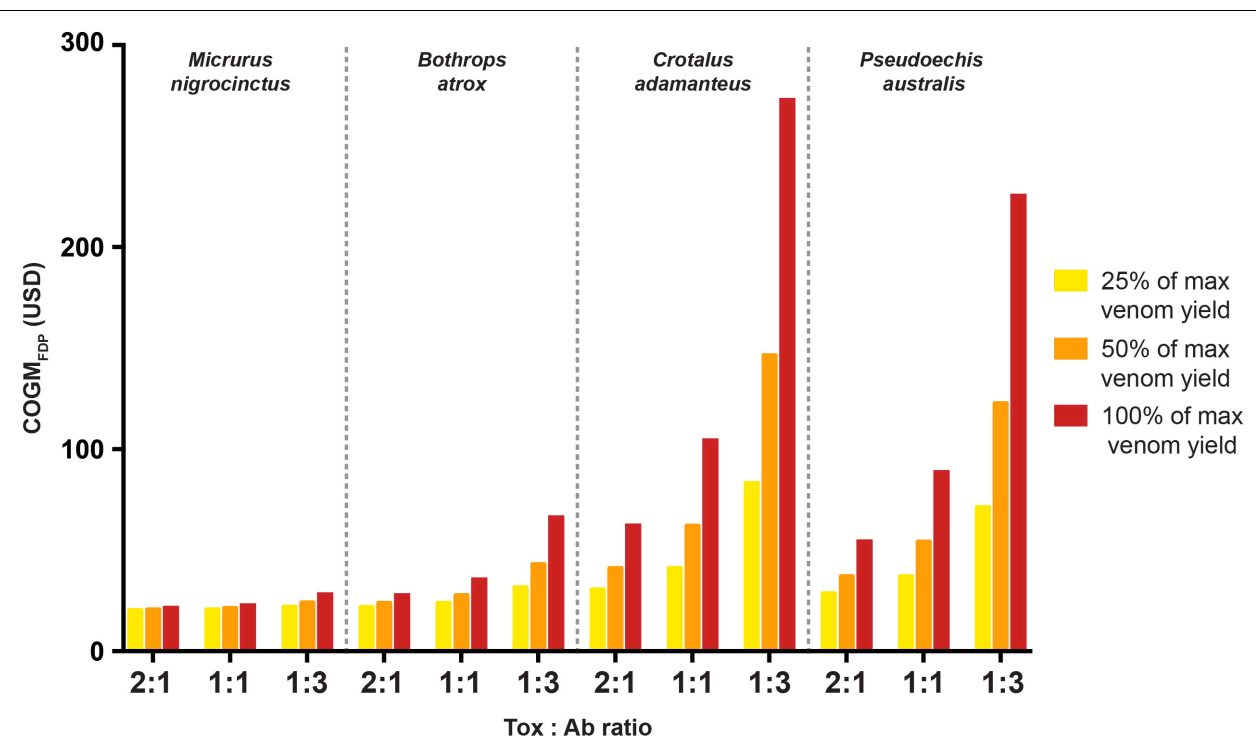

FIGURE 4 | Cost of monovalent recombinant antivenoms against four representative species of venomous snakes. The calculations were conducted for three different toxin-to-antibody ratios (i.e., 2:1, 1:1, and 1:3) and assumed that either $25 \%$ (yellow), $50 \%$ (orange), or 100\% (red) of the maximum venom yield needs to be neutralized. The calculations are for Cost of Goods Manufactured for the Final Drug Product for a full treatment of a given snakebite (COGMFDP) and, thus, include formulation and packaging costs.

and E. carinatus) and a more complex antivenom (10 different venoms from Dendroaspis spp., Bitis spp., Naja spp., and Echis spp.) that could be indicated against bites from to the same venomous snakes as a former high-quality antivenom for subSaharan Africa (Sanofi Pasteur's FAV-Afrique). We calculated the costs for very efficacious, efficacious, and less efficacious antibodies, reflected by the toxin-to-antibody ratios $(2: 1,1: 1$, and $1: 3$, respectively). We also evaluated the impact of antibody cross-

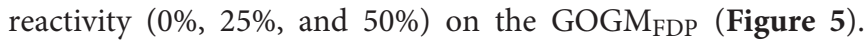
Notably, cross-reactivity appears to influence antivenom cost less than antibody efficacy, particularly in the polyvalent recombinant antivenom for the four Indian snakes. However, it appears that the impact of cross-reactivity is significantly higher when assessing more complex and expensive antivenoms, such as the polyvalent recombinant antivenom for sub-Saharan Africa. Additionally, cross-reactivity would simplify the manufacturing process, since less antibodies would need to be produced and quality control would be easier. Consequently, cross-reactivity is likely to have further indirect impact on the COGM FDP $_{\text {than }}$ just in the context of the neutralizing capacity of the recombinant antivenom. However, this is not taken into account here due to its rather speculative nature. Nevertheless, the COGM FDP for both polyvalent recombinant antivenoms compare favorably with prices of existing antivenoms. Current Indian polyvalent antivenom costs approximately USD 6.5-11 per vial, with two initial vials being recommended, but 10 vials typically being required (Theakston and Warrell, 1991; Isbister et al., 2015; Alirol et al., 2017). This equates to an antivenom price of USD 13-110 per treatment, which is comparable to both recombinant solutions containing (very) effective antibodies (2:1 and 1:1 toxin-to-antibody), with cost estimates of USD 48-84 per treatment. However, it is of note that this is not taking profit margins into account for the recombinant antivenoms, as well as indirect costs affected by efficacy and safety of treatments

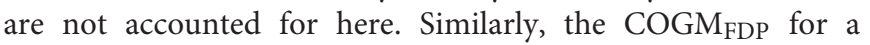
recombinant antivenom appears to compare favorably to the price of the former high-quality polyvalent antivenom for subSaharan Africa, FAV-Afrique. Although no longer in production, FAV-Afrique used to be priced between USD 60-140 per vial, and treatments typically required $2-8$ vials, resulting in the treatment price ranging from USD 120-1120 (Trop, 2011; Brown, 2012; Harrison et al., 2017). This price is comparable to both recombinant antivenoms containing (very) effective antibodies (2:1 and 1:1 toxin-to-antibody), with cost estimates of USD 180-465 per treatment. Depending on the degree of crossreactivity, a recombinant antivenom product with less efficacious antibodies (1:3 toxin-to-antibody) would still be less expensive (at 50\% cross-reactivity), slightly more expensive (at 25\% cross-reactivity), or significantly more expensive (at $0 \%$ crossreactivity). Together, these calculations indicate that polyvalent recombinant antivenoms, even with very broad species coverage, might not only match, but also significantly lower the cost of treatment, whilst likely also providing safer and more efficacious therapy, provided that the antibodies included in the antivenoms are of high therapeutic quality and efficacy.

\section{Alternative Antitoxins and Their COGM $_{\text {FDP }}$}

IgG antibodies have many advantages, such as a long serum halflife, extensive clinical validation, and established manufacturing strategies. Yet, other smaller formats, including Fabs, scFvs, DARPins, nanobodies, and Avimers, have their own set of advantages (Jenkins et al., 2019; Knudsen et al., 2019). Indeed, these formats have more binding sites per mass unit due 


\section{A} Indian polyvalent (four venoms)

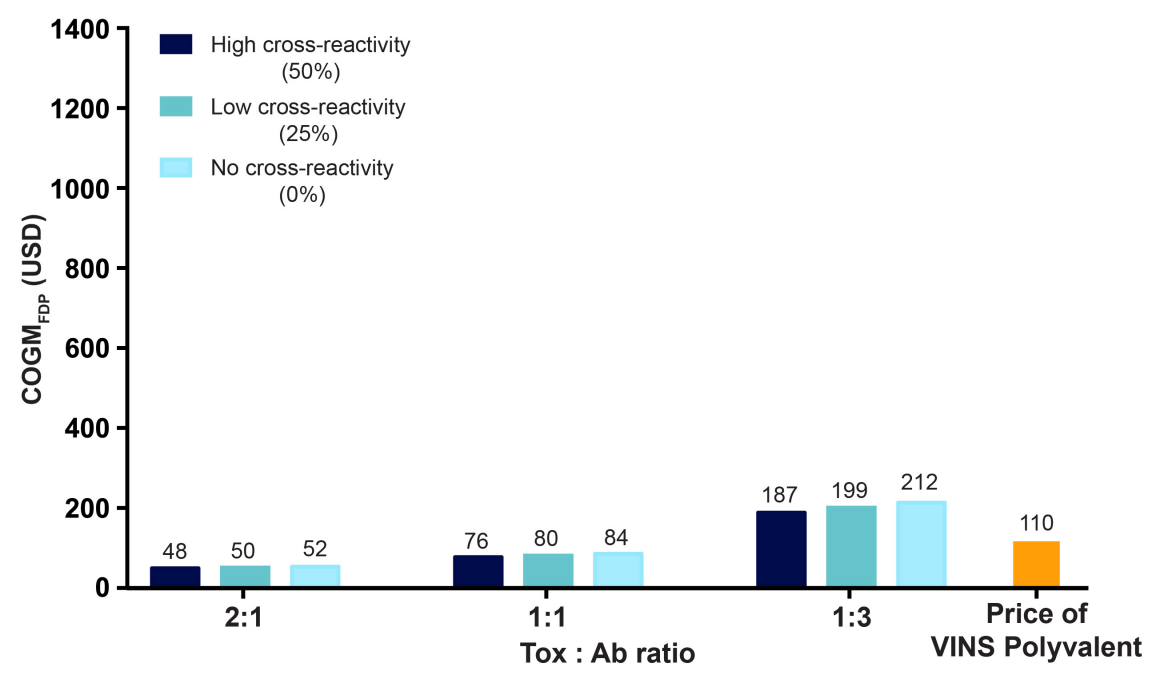

B

African polyvalent (ten venoms)

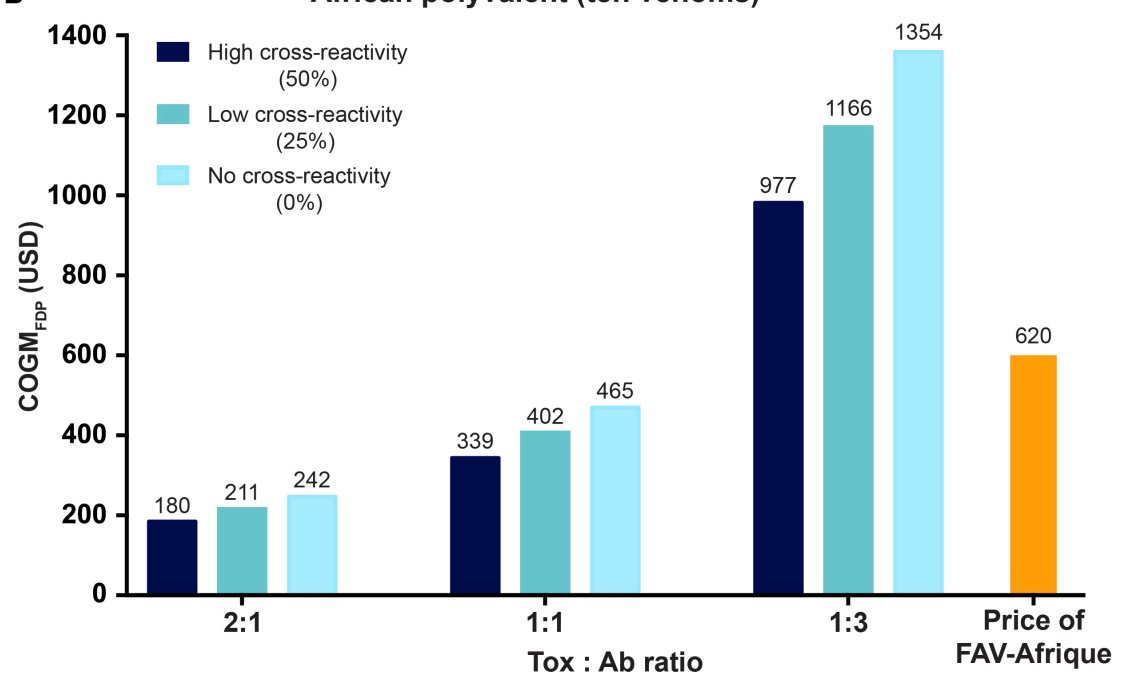

FIGURE 5 | Cost estimates for two polyvalent recombinant antivenoms. (A) Putative Cost of Goods Manufactured for the Final Drug Product (COGM FDP) for a recombinant antivenom that can neutralize the venoms of the four most medically relevant snakes in India (i.e., Naja naja, Bungarus caeruleus, Echis carinatus, and Daboia russelii). (B) Cost estimates for a recombinant antivenom that can neutralize 10 different species of snakes in sub-Saharan Africa (i.e., Bitis arietans, $B$. gabonica, E. leuconogaster, E. ocellatus, Dendroaspis polylepis, D. jamesoni, D. viridis, N. haje, N. nigricollis, and N. melanoleuca). All of the calculations are conducted for three different toxin-to-antibody ratios $(2: 1,1: 1$, and 1:3). Furthermore, potential cross-reactivity of the monoclonal antibodies present in the recombinant antivenoms against different venom toxins is also included, with estimates including 0\% (light blue), 25\% (dark turquoise), and 50\% (dark blue) cross-reactivity. The costs are calculated for the final drug product, which includes formulation costs. The price per treatment for two animal plasma-derived polyvalent antivenoms for both India (VINS polyvalent) and sub-Saharan Africa (FAV-Afrique - out of production) are also provided for comparison (please note that these are sales prices, which also reflect financial parameters other than COGM alone, such as sales, distribution, indirect costs, and profit margin).

to their smaller molar mass, which could have a favorable influence on cost dynamics, as the amount of antitoxin required for neutralizing a given venom may be less (in terms of gram). Consequently, this could lower the final product cost (assuming equimolarity for antivenoms products). Therefore, using the previously mentioned formats we calculated the cost of a polyvalent recombinant antivenom for sub-Saharan Africa, assuming both an "expected" and "worst case scenario" of 1:1 and 1:3 toxin-to-antibody ratios respectively; the former assumes
$25 \%$ cross-reactivity, while the latter is calculated without any cross-reactivity (Figure 6). We found a major difference in $\mathrm{COGM}_{\mathrm{FDP}}$ between all scaffolds and a linear relationship between size of the scaffold and the cost of the final drug product. Thus, Avimers were the most inexpensive in both scenarios with an estimated cost of USD 30/56 (expected/worst case) per treatment and IgGs the most expensive with a cost of USD 402/1354 (expected/worst case) per treatment. This demonstrates that even in rare cases where IgGs might not be financially 
viable, alternative antitoxin scaffolds could be used instead to achieve economic viability. There are, however, other variables to consider when calculating the costs of a recombinant antivenom using alternative antitoxin scaffolds, such as their short halflife (likely requiring administration of larger amounts of the antivenom) and different volumes of distribution (Jenkins et al., 2019). Many alternative antitoxin scaffolds can be produced via microbial expression, rather than mammalian cell cultivation, which may have the potential to be even more cost-competitive at large production volumes. However, given the lack of manufacturing cost data for microbial expression, we decided not to overspeculate in this regard and use the same COGM $\mathrm{API}$ for all antitoxin formats (Jenkins et al., 2019). The actual costs for alternative antitoxin scaffolds may, thus, be even more attractive than presented here.

\section{Limitations of the Study}

Whilst the safety and efficacy of any therapeutic should stand at the forefront of all development considerations, it is also key that the product can be manufactured costcompetitively. Indeed, cost of manufacture is of high importance when catering to predominantly low income markets, such as those heavily affected by snakebite envenoming (Harrison et al., 2009). Consequently, we aimed to provide cost estimates for potential recombinant antivenoms to demonstrate that such products are likely to be manufacturable at a cost-competitive level to conventional antivenoms. It is, however, of note that all of our estimates rely on the industry data available to us and the assumptions provided in the methods, such as an expected annual production volume of $500 \mathrm{~kg}$ of antibodies. To address this and minimize the impact of incorrect assumptions, we aimed at providing a range of different "scenarios" for most variables included in this study. It should also be noted that the calculations are technical and based on theoretical modeling, which might limit the applicability of the findings to the field. Therefore, the numbers provided here should not be
A

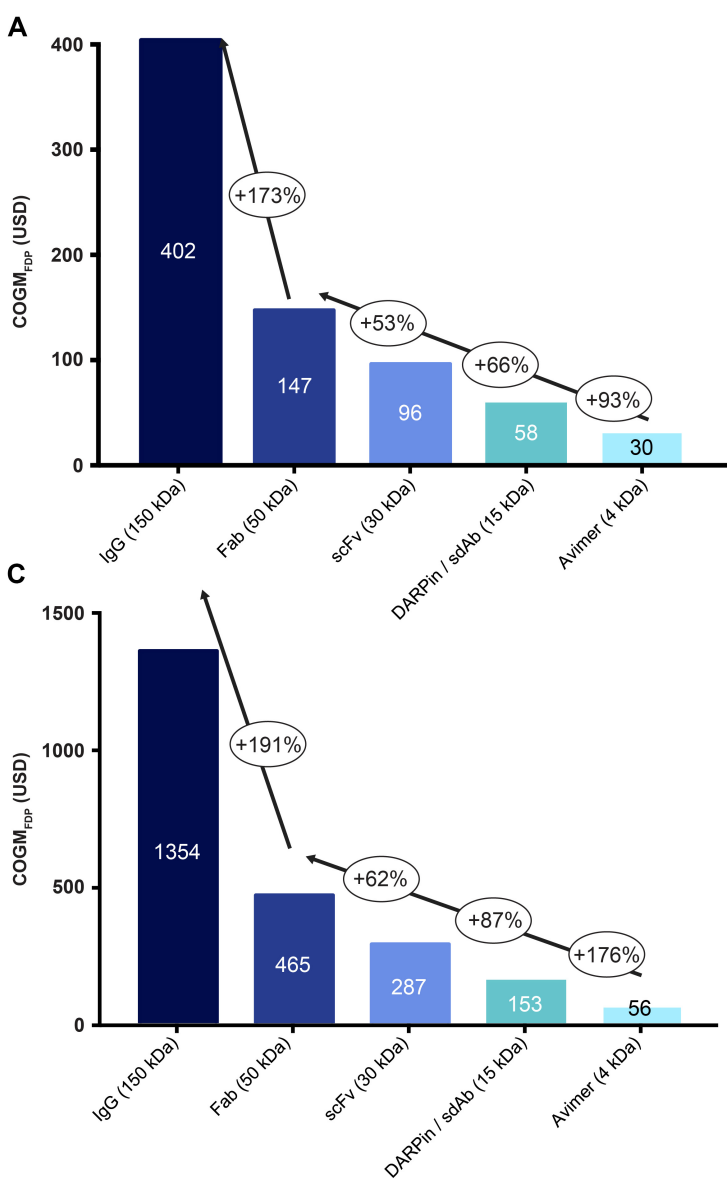

B

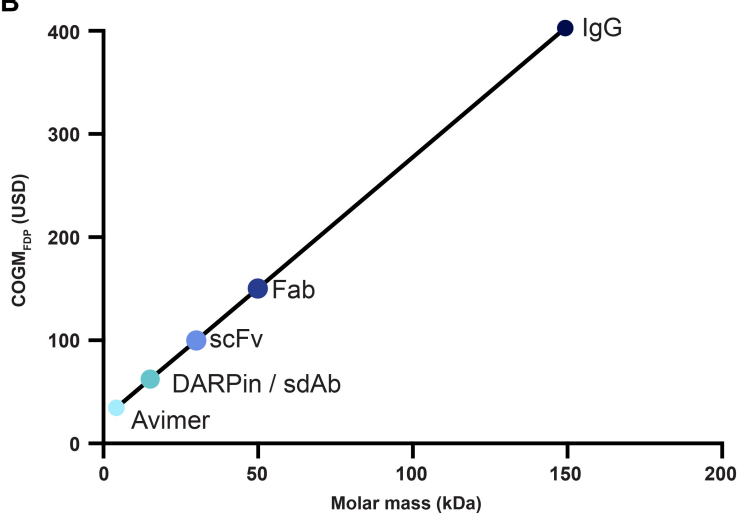

D

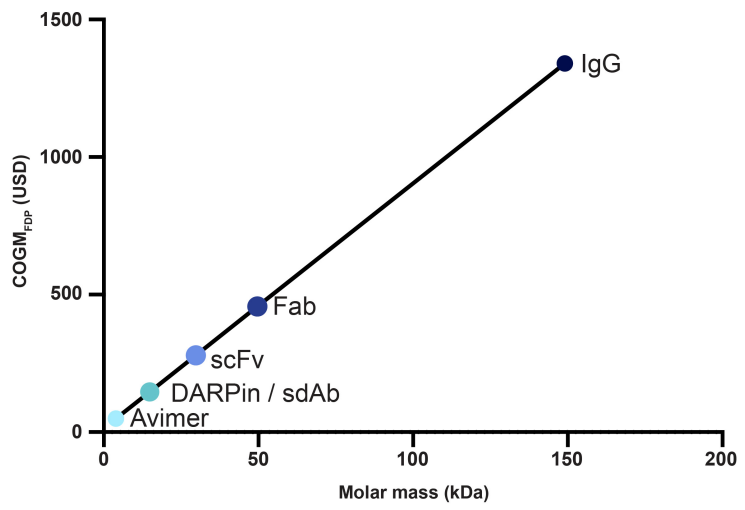

FIGURE 6 | The influence of molar mass of the antitoxin on the cost of recombinant antivenoms for different antibody formats and alternative antitoxin scaffolds. Here, we calculated the cost of a polyvalent recombinant antivenom for sub-Saharan Africa, using an "expected" (A) and a "worst case" scenario (C) of 1:1 and 1:3 toxin-to-antibody ratio, respectively; the former (A) assumes $25 \%$ cross-reactivity for the antitoxins, while the latter is calculated without any cross-reactivity. The included formats include IgG, Fab, scFv, DARPin/sdAb, and Avimer. The bubbles indicate the percentage of cost increase from one format to the next and the text in the columns indicate the cost of the final drug product. Correlation between molar masses of the different antitoxin formats and the Cost of Goods Manufactured for the Final Drug Product (COGMFDP) of the recombinant antivenom is given for both the "expected" (B) and the "worst case" scenario (D), respectively. 
seen as a definitive conclusion to the cost of manufacture for recombinant antivenoms, but rather as a rough guideline toward understanding the cost dynamics at play. Core challenges in improving the accessibility and efficacy of antivenom remain to be resolved in the management of snakebite envenoming.

\section{CONCLUSION}

New therapeutics often come with exciting treatment prospects for patients. However, it is pivotal to ensure that any new therapy is commercially viable to manufacture and distribute to the market. This is particularly important for antivenoms, which are predominantly required in impoverished regions around the globe. Therefore, in this article, we present the first ever bottom-up cost estimates for recombinant antivenoms. Whilst the numbers should not be taken as definitive conclusions and rather as estimates based on available industry data, the cost dynamics presented here should aid future research and development decisions and strategy. Together, our data indicates that innovative envenoming therapies based on monoclonal antibodies could be manufacturable at a comparable or lower cost to current antivenoms. Indeed, we found that monovalent recombinant antivenoms could be manufactured for USD 20 225 per treatment and more complex polyvalent recombinant antivenoms could be manufactured for USD 48-1354 per treatment. These numbers are slightly higher when compared to previous estimates (USD 33-350 per treatment), yet those calculations were based on a less differentiated top-down approach (Laustsen et al., 2017). Nevertheless, the COGMFDP of recombinant antivenoms falls within a similar spectrum

\section{REFERENCES}

Ainsworth, S., Petras, D., Engmark, M., Süssmuth, R. D., Whiteley, G., Albulescu, L.-O., et al. (2018). The medical threat of mamba envenoming in sub-Saharan Africa revealed by genus-wide analysis of venom composition, toxicity and antivenomics profiling of available antivenoms. J. Proteom. 172, 173-189. doi: 10.1016/j.jprot.2017.08.016

Alirol, E., Sharma, S. K., Ghimire, A., Poncet, A., Combescure, C., Thapa, C., et al. (2017). Dose of antivenom for the treatment of snakebite with neurotoxic envenoming: evidence from a randomised controlled trial in Nepal. PLoS Negl. Trop. Dis. 11:e0005612. doi: 10.1371/journal.pntd.0005612

Broad, A. J., Sutherland, S. K., and Coulter, A. R. (1979). The lethality in mice of dangerous Australian and other snake venom. Toxicon 17, 661-664. doi: 10.1016/0041-0101(79)90245-9

Brown, N. I. (2012). Consequences of neglect: analysis of the sub-saharan African snake antivenom market and the global context. PLoS Negl. Trop. Dis. 6:e1670. doi: 10.1371/journal.pntd.0001670

Calderon, H. B., Coronel, V. O. Y., Rey, O. A. C., Alave, E. G. C., Duran, W. J. L., Rojas, C. P., et al. (2020). Development of nanobodies against hemorrhagic and myotoxic components of bothrops atrox snake venom. Front. Immunol. 11:655. doi: 10.3389/fimmu.2020.00655

Calvete, J. J., Juárez, P., and Sanz, L. (2007a). Snake venomics. Strategy and applications. J. Mass Spectrom. 42, 1405-1414. doi: 10.1002/jms.1242

Calvete, J. J., Marcinkiewicz, C., and Sanz, L. (2007b). Snake venomics of bitis gabonica gabonica. protein family composition, subunit organization of venom toxins, and characterization of dimeric disintegrins bitisgabonin-1 and bitisgabonin-2. J. Proteome Res. 6, 326-336. doi: 10.1021/pr060494k

Calvete, J. J., Sanz, L., Pérez, A., Borges, A., Vargas, A. M., Lomonte, B., et al. (2011). Snake population venomics and antivenomics of Bothrops as the prices of currently employed antivenoms (USD 131120 per treatment). Finally, manufacturing costs may be even lower for recombinant antivenoms based on alternative antitoxin scaffolds, such as DARPins and nanobodies, which may warrant further research efforts in experimenting with these proteins as putative antitoxins. Given the likelihood of recombinant antivenoms being cost-competitive, alongside their potential therapeutic benefits over conventional antivenoms, further investigation and development of such novel snakebite therapeutics seems warranted.

\section{DATA AVAILABILITY STATEMENT}

The raw data and calculations supporting the conclusions of this article are available upon request to the authors.

\section{AUTHOR CONTRIBUTIONS}

TJ and AL conceived this study. TJ conducted the analyses and prepared the figures, Both authors drafted and finalized the manuscript.

\section{FUNDING}

This study was funded by the Villum Foundation grant no. 00025302 (AL) and the European Union's Horizon 2020 research and innovation program under the Marie Sklodowska-Curie (COFUNDfellowsDTU) grant no. 713683 (TJ). atrox: Paedomorphism along its transamazonian dispersal and implications of geographic venom variability on snakebite management. J. Proteom. 74, 510-527. doi: 10.1016/j.jprot.2011.01.003

Chacón, D., Rodríguez, S., Arias, J., Solano, G., Bonilla, F., and Gómez, A. (2012). Maintaining coral snakes (Micrurus nigrocinctus, Serpentes: Elapidae) for venom production on an alternative fish-based diet. Toxicon 60, 249-253. doi: 10.1016/j.toxicon.2012.04.332

Chippaux, J. P. (2017). Snakebite envenomation turns again into a neglected tropical disease! J. Venom Anim. Toxins Trop. Dis. 23:38. doi: 10.1186/s40409017-0127-6

Dutta, S., Chanda, A., Kalita, B., Islam, T., Patra, A., and Mukherjee, A. K. (2017). Proteomic analysis to unravel the complex venom proteome of eastern india naja naja: correlation of venom composition with its biochemical and pharmacological properties. J. Proteom. 156, 29-39. doi: 10.1016/j.jprot.2016. 12.018

Farid, S. S. (2007). Process economics of industrial monoclonal antibody manufacture. J. Chromatogr. B 848, 8-18. doi: 10.1016/j.jchromb.2006.07.037

Fernández, J., Alape-Girón, A., Angulo, Y., Sanz, L., Gutiérrez, J. M., Calvete, J. J., et al. (2011). Venomic and antivenomic analyses of the central american coral snake, Micrurus nigrocinctus (Elapidae). J. Proteome Res. 10, 1816-1827. doi: $10.1021 /$ pr101091a

Ferraz, C. R., Arrahman, A., Xie, C., Casewell, N. R., Lewis, R. J., Kool, J., et al. (2019). Multifunctional toxins in snake venoms and therapeutic implications: from pain to hemorrhage and necrosis. Front. Ecol. Evol. 7:218. doi: 10.3389/ fevo.2019.00218

Georgieva, D., Seifert, J., Öhler, M., von Bergen, M., Spencer, P., Arni, R. K., et al. (2011). Pseudechis australis venomics: adaptation for a defense against microbial pathogens and recruitment of body transferrin. J. Proteome Res. 10, 2440-2464. doi: 10.1021/pr101248e 
Gutiérrez, J. M., Calvete, J. J., Habib, A. G., Harrison, R. A., Williams, D. J., and Warrell, D. A. (2017). Snakebite envenoming. Nat. Rev. Dis. Primer. 3:17063. doi: $10.1038 /$ nrdp. 2017.63

Hammerschmidt, N., Tscheliessnig, A., Sommer, R., Helk, B., and Jungbauer, A. (2014). Economics of recombinant antibody production processes at various scales: industry-standard compared to continuous precipitation. Biotechnol. J. 9, 766-775. doi: 10.1002/biot.201300480

Harrison, R. A., Hargreaves, A., Wagstaff, S. C., Faragher, B., and Lalloo, D. G. (2009). Snake envenoming: a disease of poverty. PLoS Negl. Trop. Dis. 3:e569. doi: 10.1371/journal.pntd.0000569

Harrison, R. A., Oluoch, G. O., Ainsworth, S., Alsolaiss, J., Bolton, F., Arias, A., et al. (2017). Preclinical antivenom-efficacy testing reveals potentially disturbing deficiencies of snakebite treatment capability in East Africa. PLoS Negl. Trop. Dis. 11:e0005969. doi: 10.1371/journal.pntd.0005969

Harvey, A. L. (2001). Twenty years of dendrotoxins. Toxicon 39, 15-26. doi: 10. 1016/S0041-0101(00)00162-8

Isbister, G. K., Maduwage, K., Saiao, A., Buckley, N. A., Jayamanne, S. F., Seyed, S., et al. (2015). Population pharmacokinetics of an Indian F (ab') 2 snake antivenom in patients with Russell's viper (Daboia russelii) bites. PLoS Negl. Trop. Dis. 9:e0003873. doi: 10.1371/journal.pntd.0003873

Jenkins, T. P., Fryer, T., Dehli, R. I., Jürgensen, J. A., Fuglsang-Madsen, A., Føns, S., et al. (2019). Toxin neutralization using alternative binding proteins. Toxins 11:53. doi: 10.3390/toxins 11010053

Juárez, P., Wagstaff, S. C., Oliver, J., Sanz, L., Harrison, R. A., and Calvete, J. J. (2006). Molecular Cloning of disintegrin-like transcript BA-5A from a Bitis arietans venom gland cDNA library: a putative intermediate in the evolution of the long-chain disintegrin bitistatin. J. Mol. Evol. 63, 142-152. doi: 10.1007/ s00239-005-0268-z

Kalita, B., Patra, A., Das, A., and Mukherjee, A. K. (2018). Proteomic analysis and immuno-profiling of eastern india russell's viper (Daboia russelii) venom: correlation between RVV composition and clinical manifestations post RV bite. J. Proteome Res. 17, 2819-2833. doi: 10.1021/acs.jproteome.8b00291 doi: 10.1021/acs.jproteome.8b00291

Kini, R. M., Sidhu, S. S., and Laustsen, A. H. (2018). Biosynthetic oligoclonal antivenom (BOA) for snakebite and next-generation treatments for snakebite victims. Toxins 10:534. doi: 10.3390/toxins10120534

Klutz, S., Magnus, J., Lobedann, M., Schwan, P., Maiser, B., Niklas, J., et al. (2015). Developing the biofacility of the future based on continuous processing and single-use technology. J. Biotechnol. 213, 120-130. doi: 10.1016/j.jbiotec.2015. 06.388

Knudsen, C., and Laustsen, A. H. (2018). Recent advances in next generation snakebite antivenoms. Trop. Med. Infect. Dis. 3:42. doi: 10.3390/tropicalmed3020042

Knudsen, C., Ledsgaard, L., Dehli, R. I., Ahmadi, S., Sørensen, C. V., and Laustsen, A. H. (2019). Engineering and design considerations for next-generation snakebite antivenoms. Toxicon 167, 67-75. doi: 10.1016/j.toxicon.2019.06.005

Latifi, M. (1984). Variation in yield and lethality of venoms from Iranian snakes. Toxicon 22, 373-380. doi: 10.1016/0041-0101(84)90081-3

Lauridsen, L. P., Laustsen, A. H., Lomonte, B., and Gutiérrez, J. M. (2017). Exploring the venom of the forest cobra snake: Toxicovenomics and antivenom profiling of Naja melanoleuca. J. Proteomics 150, 98-108. doi: 10.1016/j.jprot. 2016.08.024

Laustsen, A. H. (2016). Recombinant Antivenoms. Ph.D. thesis, University of Copenhagen, Denmark.

Laustsen, A. H. (2019). How can monoclonal antibodies be harnessed against neglected tropical diseases and other infectious diseases? Expert. Opin. Drug Discov. 14, 1103-1112. doi: 10.1080/17460441.2019.164 6723

Laustsen, A. H., and Dorrestijn, N. (2018). Integrating engineering, manufacturing, and regulatory considerations in the development of novel antivenoms. Toxins 10:309. doi: 10.3390/toxins 10080309

Laustsen, A. H., Johansen, K. H., Engmark, M., and Andersen, M. R. (2016). Snakebites: costing recombinant antivenoms. Nature 538:41. doi: 10.1038/ 538041e

Laustsen, A. H., Johansen, K. H., Engmark, M., and Andersen, M. R. (2017). Recombinant snakebite antivenoms: a cost-competitive solution to a neglected tropical disease? PLoS Negl. Trop. Dis. 11:e0005361. doi: 10.1371/journal.pntd. 0005361
Laustsen, A. H., Karatt-Vellatt, A., Masters, E. W., Arias, A. S., Pus, U., Knudsen, C., et al. (2018). In vivo neutralization of dendrotoxin-mediated neurotoxicity of black mamba venom by oligoclonal human IgG antibodies. Nat. Commun. 9:3928. doi: 10.1038/s41467-018-06086-4

Malih, I., Ahmad rusmili, M. R., Tee, T. Y., Saile, R., Ghalim, N., and Othman, I. (2014). Proteomic analysis of Moroccan cobra Naja haje legionis venom using tandem mass spectrometry. J. Proteom. 96, 240-252. doi: 10.1016/j.jprot.2013. 11.012

Margres, M. J., McGivern, J. J., Wray, K. P., Seavy, M., Calvin, K., and Rokyta, D. R. (2014). Linking the transcriptome and proteome to characterize the venom of the eastern diamondback rattlesnake (Crotalus adamanteus). J. Proteom. 96, 145-158. doi: 10.1016/j.jprot.2013.11.001

Marsh, N. A., and Whaler, B. C. (1984). The gaboon viper (Bitis gabonica): its biology, venom components and toxinology. Toxicon 22, 669-694. doi: 10. 1016/0041-0101(84)90152-1

Mirtschin, P. J., Dunstan, N., Hough, B., Hamilton, E., Klein, S., Lucas, J., et al. (2006). Venom yields from Australian and some other species of snakes. Ecotoxicology 15, 531-538. doi: 10.1007/s10646-006-0089-x

O'Shea, M. (2005). Venomous Snakes Of The World. Princeton, NJ: Princeton University Press.

Patra, A., Chanda, A., and Mukherjee, A. K. (2019). Quantitative proteomic analysis of venom from Southern India common krait (Bungarus caeruleus) and identification of poorly immunogenic toxins by immune-profiling against commercial antivenom. Expert Rev. Proteom. 16, 457-469. doi: 10.1080/ 14789450.2019.1609945

Patra, A., Kalita, B., Chanda, A., and Mukherjee, A. K. (2017). Proteomics and antivenomics of Echis carinatus carinatus venom: correlation with pharmacological properties and pathophysiology of envenomation. Sci. Rep. 7, $1-17$.

Petras, D., Heiss, P., Harrison, R. A., Süssmuth, R. D., and Calvete, J. J. (2016). Topdown venomics of the East African green mamba, Dendroaspis angusticeps, and the black mamba, Dendroaspis polylepis, highlight the complexity of their toxin arsenals. J. Proteom. 146, 148-164. doi: 10.1016/j.jprot.2016.06.018

Petras, D., Sanz, L., Segura, Á, Herrera, M., Villalta, M., Solano, D., et al. (2011). Snake venomics of African spitting cobras: toxin composition and assessment of congeneric cross-reactivity of the pan-African EchiTAb-Plus-ICP antivenom by antivenomics and neutralization approaches. J. Proteome Res. 10, 1266-1280. doi: 10.1021/pr101040f

Rasmussen, S. K., Næsted, H., Müller, C., Tolstrup, A. B., and Frandsen, T. P. (2012). Recombinant antibody mixtures: production strategies and cost considerations. Archiv. Biochem. Biophys. 526, 139-145. doi: 10.1016/j.abb. 2012.07.001

Richard, G., Meyers, A. J., McLean, M. D., Arbabi-Ghahroudi, M., MacKenzie, R., and Hall, J. C. (2013). In vivo neutralization of $\alpha$-cobratoxin with high-affinity llama single-domain antibodies (VHHs) and a VHH-Fc antibody. PLoS One 8:e69495. doi: 10.1371/journal.pone.0069495

Serrano, S. M. T. (2012). The long road of research on snake venom serine proteinases. Toxicon 62, 19-26. doi: 10.1016/j.toxicon.2012.09.003

Silva, L. C., Pucca, M. B., Pessenda, G., Campos, L. B., Martinez, E. Z., Cerni, F. A., et al. (2018). Discovery of human scFvs that cross-neutralize the toxic effects of B. jararacussu and C. d. terrificus venoms. Acta Trop. 177, 66-73. doi: 10.1016/j.actatropica.2017.09.001

Strong, P. N., Goerke, J., Oberg, S. G., and Kelly, R. B. (1976). beta-Bungarotoxin, a pre-synaptic toxin with enzymatic activity. Proc. Natl. Acad. Sci. U.S.A. 73, 178-182. doi: 10.1073/pnas.73.1.178

Theakston, R. D. G., and Warrell, D. A. (1991). Antivenoms: a list of hyperimmune sera currently available for the treatment of envenoming by bites and stings. Toxicon 29, 1419-1470. doi: 10.1016/0041-0101(91)90002-9

Trop, M. (2011). FAV-Afrique ${ }^{\circledR}$ : un sérum antivenimeux polyvalent employé en Afrique et en Europe. Méd. Trop. 71, 537-540.

Wagstaff, S. C., Sanz, L., Juárez, P., Harrison, R. A., and Calvete, J. J. (2009) Combined snake venomics and venom gland transcriptomic analysis of the ocellated carpet viper, Echis ocellatus. J. Proteom. 71, 609-623. doi: 10.1016/j. jprot.2008.10.003

Walsh, G. (2014). Biopharmaceutical benchmarks. Nat. Biotechnol. 32, 992-1000. doi: $10.1038 /$ nbt.3040

Williams, D. J., Faiz, M. A., Abela-Ridder, B., Ainsworth, S., Bulfone, T. C., Nickerson, A. D., et al. (2019). Strategy for a globally coordinated response to 
a priority neglected tropical disease: snakebite envenoming. PLoS Negl. Trop. Dis. 13:e0007059. doi: 10.1371/journal.pntd.0007059

Williams, D. J., Gutiérrez, J. M., Calvete, J. J., Wüster, W., Ratanabanangkoon, K., Paiva, O., et al. (2011). Ending the drought: new strategies for improving the flow of affordable, effective antivenoms in Asia and Africa. J. Proteom. 74, $1735-1767$.

Wong, K. Y., Tan, C. H., and Tan, N. H. (2016). Venom and purified toxins of the spectacled cobra (Naja naja) from Pakistan: insights into toxicity and antivenom neutralization. Am. J. Trop. Med. Hyg. 94, 1392-1399.
Conflict of Interest: The authors declare that the research was conducted in the absence of any commercial or financial relationships that could be construed as a potential conflict of interest.

Copyright $\odot 2020$ Jenkins and Laustsen. This is an open-access article distributed under the terms of the Creative Commons Attribution License (CC BY). The use, distribution or reproduction in other forums is permitted, provided the original author(s) and the copyright owner(s) are credited and that the original publication in this journal is cited, in accordance with accepted academic practice. No use, distribution or reproduction is permitted which does not comply with these terms. 